\title{
Reform and Development of Bulgarian Cooperatives
}

\author{
Wang Peng ${ }^{1,2}$ \\ 1. Business School, Hohai University, NanJing, P.R.China \\ 2. All China Federation of Supply and Marketing Cooperatives, BeiJing, P.R.China
}

\begin{abstract}
Bulgarian cooperatives have formed a model of reform integrating optimized laws and regulations, governance, market operation and expanded services in the transformation from the planned economy to the market-oriented economy. This paper takes the consumer cooperatives of Bulgaria as an example to find out how to accomplish the reform based on the abovementioned model, providing references for the reform and development of cooperatives in China.
\end{abstract}

\section{INTRODUCTION}

Since the establishment of the Rochdale Equitable Pioneers Society of in 1844, the first cooperative in the world based in Rochdale of England, cooperatives have been developing for 176 years, playing an irreplaceable role in boosting employment, eliminating poverty and promoting social harmony worldwide ${ }^{[1]}$. The cooperatives in eastern Europe, represented by Bulgarian cooperatives, experienced the transformation from planned economy to market economy, and have been playing a crucial role in the political, economic and social development of the country. The active explorations have resulted in a mature model of reform for cooperatives in the context of economic transformation.

\section{THE MOdel OF REFORM FOR BULGARIAN CoOperatives}

\subsection{Development of Bulgarian cooperatives}

Located in the southeast of Europe, Bulgaria covers an area of 110,000 square kilometers and has a population of about 7 million. It is a traditional agricultural country with abundant agricultural and forestry resources. Cooperatives have been playing an important role in social, political and economic development. The first cooperative in Bulgaria was established in 1890 , and the first national cooperative association was established in 1895 , which joined the International Co-operative Alliance (ICA) in 1902.

In 1946, the People's Republic of Bulgaria was established with a planned economic policy, and the development of cooperatives was highly valued by the government. In 1947, with the support of the government, numerous cooperatives in Bulgaria joined together to form the Central Cooperative Union, then the Bulgarian cooperatives have developed rapidly and played an important role in agriculture, rural areas and farmers. In 1980 s, $90 \%$ of the commercial and catering services in Bulgaria's rural areas and small and medium-sized towns were operated by consumer cooperatives, with their retail sales accounting for $86 \%$ of the total retail sales of rural goods, accounting for $35 \%$ of the national retail sales. The number of members once accounted for $1 / 4$ of the national total population ${ }^{[2]}$. In addition to being responsible for the consumption of goods and services in rural areas and small and medium-sized towns across the country, the cooperatives also produce canned food, nonalcoholic beverages, bread and various kinds of small commodities

In the 1990s, Bulgaria changed its name to the Republic of Bulgaria, and started to implement market economy, forcing domestic cooperatives to transform from organizations with governmental support in the planned economy to competitors in the market economy advocating fair competition. Now there are four national cooperatives in Bulgaria, including consumer cooperatives, agricultural cooperatives, self-employed joint cooperatives, and national joint cooperatives for the disabled. Among them, consumer cooperatives are the largest, with business concentrating on chain sales. Its reforms are the most representative and most representative of the situation of cooperative reform in Bulgaria.

\subsection{The Consumer Cooperative Reform Model}

The benefits brought by the planned economy were eliminated by the implementation of the market economy, forcing the consumer cooperatives into a dilemma. In recent years, they have been actively exploring reform and development, and proposed a reform plan based on 
strategic management of enterprises, serving as a model of Bulgarian cooperative reform.(Fig.1)

In the context of planned economy, the consumer cooperatives in Bulgaria were funded by the government and granted with administrative powers. In fact, it was not a pure market-oriented economic organization. The implementation of market economy forced the consumer cooperatives to participate in market competition. The cooperatives analyzed opportunities and threats from the external environment and evaluated its strengths and weaknesses based on theories of enterprise strategic management in the western world. The cooperatives enhanced its identity as a cooperative economic organization via reforms of governance mechanism, operation, business model and incentives. With these efforts, these cooperatives maintained a balance in the distribution of social resources and bridged the gap between the rich and poor. The reforms included adjustment of laws and regulations governing the cooperatives, optimized governance mechanism and market operation, as well as expanded business and services. The reform placed much emphasis on the control of the process, evaluation of the results and constant correction and adjustment.

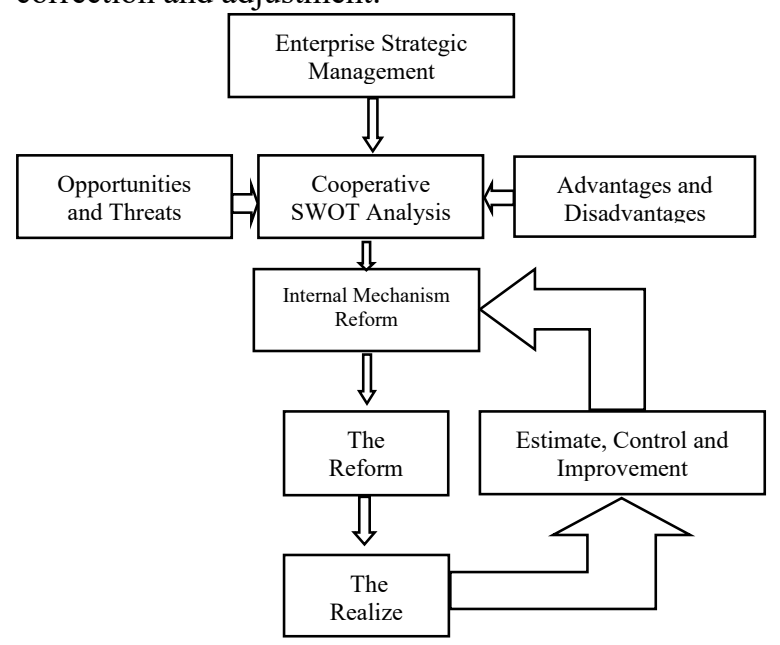

Fig.1 Model of Cooperative Reform in Bulgaria

The SWOT analysis identified the complete organization and the status of the consumer cooperatives as the largest domestic chain stores, both of which were advantages of the cooperatives. The branches of the cooperative were scattered in the rural area, with strong influence in the local area. However, the operation of the cooperatives was challenged by the economic and social transformation, with problems like immature business model, aging staff members and shortage of professionals. There are still plenty of opportunities and relatively few competitors as economic transformation continues in this country, paving way for the reform. However, when Bulgaria joined in EU in 2007, the giant retailers in EU and around the world were striving to grab a share of the market, who could be a strong competitor to the consumer cooperatives in the future. There were challenges for the reform, too. It is necessary to give a full play to the cooperatives as an enterprise and social organization, enhance its social functions and promote sustainable development. The key to the success of the reform lies in effective evaluation, control and improvement of the reform to ensure consistency, efficiency and fairness as the core of the organization, and safeguard the interests of the owners. In this way, the cooperatives would help bridge the gap between the rich and poor, and improve the livelihood of people.

\section{APPROACHES TO REFORM BULGARIAN COOPERATIVES}

\subsection{Revise the Cooperatives Law and make clear the dominant position of the marke}

The first Cooperative Law in Bulgaria was promulgated in 1907. After the implementation of market economy, the state continuously revised, supplemented and improved the Cooperative Law between 1999 and 2007, redefining cooperatives and offering more government support and encouragement. Efforts were also made to regulate the initiation, merger, termination and management of cooperatives, the qualifications, rights and obligations of members, cooperative enterprises, cooperative associations, as well as justice and supervision. According to the revised Cooperative Law, the consumer cooperatives and other cooperative organizations were endowed with the same market position as other market organizations, and the internal operation has been regulated on the basis of law.

\subsection{Optimize the governance structure to improve democracy and integration of the organization}

Taking the consumer cooperatives as an example. The Central Cooperative Alliance represents the common interests of members at the national level, while at the provincial level, 29 district associations have their own independent legal person. Under the management of provincial cooperatives, 690 grass-roots consumer cooperatives have been established and operated in accordance with the Cooperative Law. Under the leadership of the Central Cooperative Alliance, we should implement a unified policy, protect the interests of all member cooperatives, and give more support to the smallscale cooperatives, thus improving the overall strength of cooperatives, encouraging members to participate in the cooperatives and enhancing its social influence. (Fig.2) 


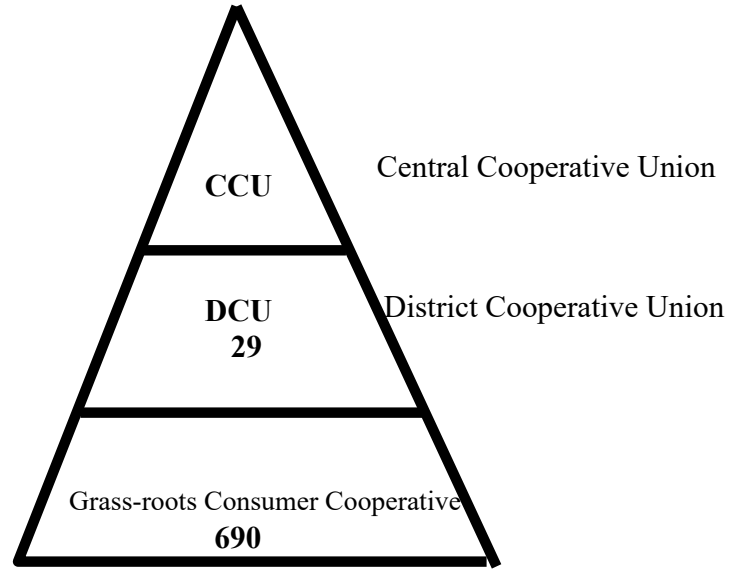

Fig.2 Structural of Bulgarian Consumer Cooperative

\subsection{Focus on strategic planning}

The cooperatives abandoned the administrative operation model adopted by the planned economy and embraced the market-oriented ideology. The Central Cooperative Alliance of Consumer Cooperatives proposed the Development Strategy by 2030 based on the consensus of consumer cooperatives at all levels and analysis of the management and operational risks. The plan covers eight fields, including trade, agriculture and forestry, agricultural products procurement, tourism and rehabilitation centers, financial stability, finance, marketing and incentive mechanism in the short, medium and long term. The human resources management needs to focus on the attraction of young members, enhancement of ties between members, as well as their career development and social values. Ensure the proportion of young people in the management team, and encourage young people to understand and learn the management model of cooperatives through special training. The talent introduction policies such as the program of "Join Cooperatives Together" simplified application procedures, which is conducive to attracting more young people to the cooperatives.

\subsection{Extensive participation in social services to actively promote the culture and principle of the cooperatives, and develop diversified and innovative business}

The consumer cooperatives ensure consistency in the external image of cooperatives at all levels by unified image, propaganda and marketing standards. By sponsoring schools and orphanages, building monuments and establishing cooperative museums, it is better known by the public, who come to understand the characteristics and advantages of cooperatives as a self-help organization of vulnerable groups and industries. In terms of operation, the business has been expanded to the processing of daily necessities, such as bread processing, mineral water production, essential oil production, wine processing, etc., and has been developing towards the whole industrial chain of planting, production, warehousing, transportation and sales. At the same time, the Central Cooperative
Alliance also has businesses such as rehabilitation, tourism and hotels, providing various services for its members and the public.

Through the reform, the consumer cooperatives in Bulgaria currently have developed 120,000 members, 6,000 employees and 695 cooperative stores across the country, providing 22 million services every year. There are 500,000 Bulgarians coming into contact with their products on a daily basis. At the same time, consumer cooperatives have the widest coverage among the 30 chain stores and enterprises in Bulgaria, and serves as the only sales organization that operates at the rural grassroots level. There are 2300 service centers across the country, of which two-thirds were distributed in remote rural areas, providing farmers with cheap bread and other food supplies. Relying on the operating service outlets, 6000 stable jobs were guaranteed, especially during the economic crisis, which made great contributions to employment and poverty alleviation.

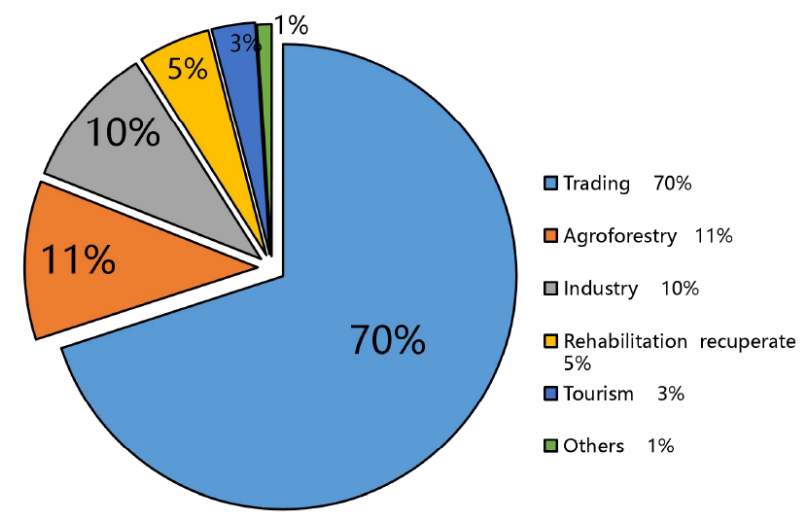

Fig.3 Composition of Business and Income of Central Cooperatives in Bulgaria

\section{Conclusion AND Discussion}

\subsection{The legal system is the guarantee for the development of cooperatives}

The cooperatives in Bulgaria have suffered from political and economic crisis, and have developed the ability to adjust to changes of social environment. They have always played an active role in political, social and economic development, and benefited from the optimized legal framework of cooperatives. It was until July 1, 2007 that China promulgated the Law on Farmers' Cooperatives, and the largest cooperative economic organization-the supply and marketing cooperatives are still striving to promulgate the Regulations on Supply and Marketing Cooperatives. In the long run, the government must improve the legal system of cooperatives as soon as possible, and introduce the legal system of cooperatives based on the Cooperative Law, thus providing a healthy and standardized legal environment for the development of various cooperative organizations. 


\subsection{Support the construction of cooperative organizations and focus on strategic planning}

At present, there are generally two types of cooperatives in China. One is the farmers' cooperatives established in accordance with the Law of Farmers' Professional Cooperatives, which are mostly single-function cooperative organizations and have not yet formed regional joint organizations. These single-function organizations need the support of government to enhance ties between cooperatives so as to form joint organizations at various levels and give a full play to their functions. The other is the traditional China Supply and Marketing Cooperatives under reform, with a nationwide organizational structure from top to bottom. However, after the transformation from planned economy to market economy, administrative officers are still playing a dominant role. It is necessary to reform the organization as an equal market participant as soon as possible, restore the economic properties of cooperatives, operate the organization in a market-oriented manner, focus on strategic planning and its implementation, and ensure its leading role in serving the rural areas.

\subsection{Strengthen the propaganda of cooperatives and the cultivation of cooperative talents}

Similar to Bulgaria and other Eastern European countries, the historical practice of collectivization of Chinese agriculture and handicraft industry in the name of "cooperativization" has led to confusion of the understanding of cooperatives and suspicion of their development in the society ${ }^{[3]}$. At present, although farmers' cooperatives are flourishing in China, there is still a lack of awareness of cooperatives in society. In view of this situation, both the government and the cooperatives should step up publicity of the theory, knowledge and culture of cooperatives, so that all sectors of society have a correct understanding of cooperatives and their important economic and social role. At the same time, the government should step up its efforts to help establish cooperatives by providing non profit cooperative programs, such as the establishment of the Agricultural Cooperative Bureau in the United States, to help establish farmers' cooperatives, and training new members and providing legal assistance to the cooperative ${ }^{[4]}$. Cooperatives should also draw on the Bulgarian consumer cooperative's emphasis on human resources strategies and on attracting the younger generation to learn about and join cooperatives.

\subsection{Expand business of National China Supply and Marketing Cooperatives and build an integrated platform for agricultural services}

The international practices have proved the efficiency of cooperatives in solving problems concerning agriculture, rural areas and farmers. The development history of Chinese cooperatives is similar to that of Bulgaria and other former socialist countries in Eastern Europe. We should fully learn from the reform path of Bulgaria's consumer cooperatives, in which they extensively participate in social services and promote diversification of their business scope. At the same time, the situation of agriculture, rural areas and farmers in China is similar to the agricultural situation in developed East Asian countries such as Japan and South Korea. At present, China's farmers' cooperatives are still in the early stage of development. We also should learn from the experience of Japan and the Republic of Korea and support the establishment of National Integrated Agricultural Cooperative Organizations. It is necessary to give a full play to the role of existing national China Supply and Marketing Cooperatives related to agriculture, rural areas and farmers, accelerate reforms of policy, capital, finance and taxation, expand the business from circulation of traditional agricultural products to the whole industrial chain of agriculture, and strengthen the functions of production, supply, marketing and credit so as to build a national platform for agricultural services.

\section{REFERENCES}

1. Deng Hengshan, Wang Wenlan, The essential regulation and reality inspection of the Cooperative, Journal of Chinese Rural Economy, vol.7, pp. 1526,2017.

2. Cooperation in Bulgaria, Journal of Business Economy Forum, no. 4, pp. 49, 1984.

3. Tang Zongkun,The Essence of Cooperatives, China Intellectual Property Publishing House, Beijing, 2012.

4. Zhou Bo,Wan Xiaobing,Zhu Zhaohui,Tang Weiqing,Wan Jing, On the Development Model of Oversea Professional Cooperation of Agriculture, Journal of Jiangxi Agricultural University, vol.8,no.1, pp. $68-72,2009$.

5. The study delegation of All China Federation of Supply and Mardeting Cooperatives, The research report on the reform and practice of the governance structure and modern operating system of Bulgarian cooperatives,2019. . unpublished.

6. Hu Yuan-yuan,Wan Hong-xian,Development of German Agricultural Cooperative Economic Organizations and the Inspiration for China, Journal of Honghe University, vol.9, no. 4, pp. 62-64,2011. 